\title{
Conjunctivitis Infective, CTCAE
}

National Cancer Institute

\section{Source}

National Cancer Institute. Conjunctivitis Infective, CT CAE. NCI Thesaurus. Code C143383.

A disorder characterized by an infectious process involving the conjunctiva. Clinical

manifestations include pink or red color in the eyes. 